\title{
A formação do professor da Educação Básica entre políticas públicas e pesquisas educacionais: uma experiência no Vale do Jequitinhonha em Minas Gerais
}

Ademilson de Sousa Soares*

\section{Resumo}

O estudo apresenta reflexões acerca da natureza do ofício de professor, reafirmando o valor da pesquisa educacional como elemento de ligação entre a formação inicial do futuro docente e o exercício profissional do professor da ativa. O texto destaca a importância de que os projetos de pós-graduação em educação sejam desenvolvidos a partir do diálogo com os cursos de formação de professores e com a realidade das escolas brasileiras de Educação Básica. Além disso, o trabalho reafirma o papel indutor das políticas educacionais no sentido de aproximar a Universidade da Escola de Educação Básica como meta fundamental para a ação pública em todas as instâncias do sistema educacional brasileiro. O projeto Prodocência da UFVJM, que busca consolidar os cursos de licenciatura a partir dessa aproximação e desse diálogo, é apresentado como exemplo desse papel indutor das políticas públicas educacionais.

Palavras-chave: Educação Básica. Políticas Educacionais. Pós-graduação em Educação. Prodocência da UFVJM

\section{Introdução}

O trabalho apresenta e problematiza alguns aspectos da formação de professores quando se considera a necessidade de que haja uma maior aproximação entre as pesquisas educacionais em nível de pós-graduação e a realidade da Educação Básica brasileira. Para isso, parte de uma discussão que caracteriza o ofício de professor, a formação docente e as políticas educacionais que promovem essa

Filósofo e Doutor em Educação, professor adjunto da Faculdade de Educação - FaE/UFMG E-mail: profpaco@gmail.com 
aproximação. Em seguida, é apresentado o projeto Prodocência da UFVJM de envolvimento da Universidade com as escolas dos Vales do Jequitinhonha e Mucuri, como uma das experiências encaminhadas pela Instituição, no sentido de consolidar os cursos de formação inicial de professores a partir do paradigma da reflexão sobre a prática e da produção teórico-crítica sobre tal reflexão.

A articulação entre diferentes níveis e modalidade de ensino considera que um dos principais eixos da profissão docente foi, e continua sendo, o trabalho com os saberes escolares manifestos em disciplinas, normas, valores e conhecimentos com vistas à sua aquisição pelas novas gerações. A partir desse eixo, reconhecemos que a formação dos profissionais do magistério da Educação Básica depende de práticas de ensino e de pesquisas que reforcem experiências inovadoras e perspectivas multidisciplinares. No entanto, no contexto atual de uma sociedade "modernamente avançada", o ensino está afetado pela crise do saber. Assim, tais práticas esbarram no fato de que tanto o professor da ativa e quanto o futuro professor vivem perguntando-se: o que e a quem ensinamos? O que e como pesquisamos? Quais objetivos buscamos quando mobilizamos o desejo de crianças e jovens em torno dos saberes escolares?

Na sociedade atual, a produção de saberes é cada vez mais proliferada e disseminada. O Google, por exemplo, é uma verdadeira "máquina" de difusão de informações e de conhecimentos. No entanto, parece que tais saberes e conhecimentos estão, igualmente, cada vez mais segmentados, fragmentados e dispersos. Eles não contribuem assim dispostos, para mobilizar e unificar, senão o pensamento, pelo menos a sua força. Com efeito, tanto os conteúdos que os professores adotam e selecionam, quanto os modos de trabalhá-los com os alunos, se revelam contestados, contestáveis e incertos. Esse quadro mais geral da profissão docente abala quase irremediavelmente as próprias bases da formação escolar que assentam-se sobre a suposta transmissão dos saberes escolares às crianças e aos jovens.

Nesse contexto, a realidade do ofício de professor da Educação Infantil ao Ensino Superior revela-se complexa e por demais desafiadora. Os profissionais envolvidos com a educação das novas gerações, com a formação dos novos educadores e com as pesquisas sobre a relação entre diferentes níveis e modalidades de ensino do sistema educacional percebem o desafio, identificam a complexidade do problema e encaminham soluções possíveis dentro de cada contexto institucional específico. 


\section{0 ofício docente na escola básica: formação, trabalho e pesquisa}

O entendimento do ofício do professor da escola básica decorre de dois movimentos indissociáveis: o primeiro movimento parte da afirmação da necessidade de aproximar as pesquisas em educação do trabalho de formação inicial dos professores; o segundo parte de movimento oposto, mas não contrário, ou seja, da necessidade de aproximar a formação inicial dos professores das pesquisas em educação. $\mathrm{O}$ trabalho com a formação de novos professores exige, dentre outras coisas, o reconhecimento de que a complexidade da ação docente só será devidamente compreendida mediante cuidadosa pesquisa. Isso tudo por quê? Porque o trabalho docente supõe a construção de habilidades, conhecimentos e competências em campos diversos: competências advindas da cultura em geral, da psicopedagogia e da didática; habilidades advindas das relações humanas e da capacidade, por exemplo, de fazer a gestão das classes; conhecimentos advindos das disciplinas escolares, das diversas matérias do programa curricular, das finalidades dos sistemas escolares, das novas Tecnologias da Informação e da Comunicação - TICs, das dificuldades de aprendizagem, do ambiente familiar e sócio-cultural dos alunos. Além disso, a ação pedagógica supõe que o professor revele aptidões e atitudes próprias e necessárias ao exercício da profissão docente tais como: respeito aos alunos, habilidade de comunicação, capacidade de empatia, espírito de abertura para diferentes culturas e minorias, habilidade para colaborar com os pais e com outros atores escolares, autonomia quanto ao julgamento das necessidades dos alunos e autonomia quanto às exigências da vida escolar e social (TARDIF; LESSARD, 2008).

Diante da complexidade do trabalho docente, como compreender a difusão e adoção simplificadas de modismos pedagógicos e de soluções didáticas? Como problematizar as teorizações acadêmicas que pouco repercutem no trabalho cotidiano do professor da escola básica? Como pesquisar o repertório de exigências dirigido aos docentes quando o ofício de professor encontra-se em mutação e sob o impacto das transformações do mundo presente?

Por um lado, escolas e professores se deparam com problemas inéditos: a transformação das estruturas familiares e comunitárias; a profusão das novas Tecnologias da Informação e da Comunicação - TICs; o aumento da pobreza das crianças em famílias monoparentais; o pluralismo cultural; o relativismo 
ético; o uso de drogas pelos jovens; as mudanças agudas no mercado de trabalho; a tendência de adotar medidas para elevar o padrão da formação e controlar a qualidade; aumento dos conflitos no cotidiano escolar; tensionamentos nas relações de trabalho; restrições orçamentárias e aumento das tarefas docentes.

Por outro lado, apesar de tantas mudanças, algumas marcas do ofício perduram no tempo: a aprendizagem do ofício ocorre na prática; a experiência docente é cada vez mais valorizada; a dimensão feminina do ofício fica evidente; o individualismo de cátedra parece típico da carreira; a pouca colaboração dos pares torna-se problema congênito; o baixo conhecimento de culturas não-européias; as sociedades se globalizam, mas o professor declara-se "tradicionalista" e desconfiado. É um novo tempo em que o fazer do professor parece mais um ofício artesanal dentro da grande indústria das escolas de massas.

Assim, a formação, o trabalho e a pesquisa sobre o ofício do professor, quando articulados, põem-se à altura de desse novo tempo e acolhem o impacto cada vez mais permanente e cada vez mais profundo das mudanças nas relações pedagógicas que ocorrem na escola e fora dela. Os modos de pesquisa, os modos de ensino, os modos de aprendizagem e os modos de avaliação terão necessariamente que ser repensados, reelaborados, reconfigurados e refeitos. Quando o professor continua "ensinando" como se ensinava antigamente, ignorando o contato com as mudanças manifestas em atitudes e posturas das novas gerações, ele mostra-se resistente em relação às demandas da contemporaneidade. Os profissionais da pesquisa em educação e da formação dos futuros docentes percebem e reconhecem que esse desafio está presente em todos os níveis e em todas as modalidades de ensino.

A problemática, por exemplo, da formação inicial e continuada de professores é mundial. Em diferentes países, a questão é discutida a partir de estratégias variadas para o enfretamento de situações comuns: o financiamento para a educação encolheu, mas a carga horária do professor cresceu, tornando-se mais pesada, mais exclusivista, mais absorvente e mais exigente. Ao lado do relativo desinteresse do Estado pela escola, pela educação e pela formação dos professores, observa-se, ainda, adoção acrítica de indicadores de rendimento e de desempenho; racionalização galopante dos agentes escolares; e políticas gerenciais de prestação de contas por meio de contratos por bom resultado, que acabam por gerar um deletério processo de competição entre os estabelecimentos escolares. 
No Brasil, o impacto de tudo isso na relação entre as pesquisas em nível de pósgraduação e a formação dos professores da Educação Básica se acentua quando reconhecemos que ainda não abandonamos a intermitência de ações, de políticas e de concepções na Educação Básica, na Educação Superior e na Pós-Graduação. Nesse percurso oscilante das políticas educacionais, vivemos um enorme paradoxo: nunca diplomamos tantos mestres e doutores em educação, nunca "investimos" tanto em Educação Básica, nunca nos preocupamos tanto com a qualificação da formação dos educadores brasileiros. No entanto, continuamos com índices sofríveis de desempenho escolar entre crianças e jovens. Tal realidade paradoxal, evidenciada, por exemplo, nas políticas nacionais de avaliação escolar, constituise enorme desafio para o profissional que atua na Educação Básica e para aqueles dedicados à pós-graduação e às pesquisas em educação. Na última década, sobretudo após a aprovação da LDB em 1996, observa-se uma pluralidade de ações dispersas e desarticuladas em todo território nacional. A sensação de todos é que fizemos muito, mas melhoramos pouco. As crianças estão na escola. Estamos trabalhando em diferentes projetos. Mas o resultado de tanto esforço parece mínimo.

Na Educação Básica, por exemplo, nos últimos 20 anos, em diferentes instâncias dos sistemas municipais, estaduais e federal, inúmeras iniciativas de mudar a escola e de inovar os processos pedagógicos foram tomadas no sentido de garantir que crianças e jovens possam ter acesso à escolarização, possam permanecer pelo tempo suficiente nos espaços escolares e possam participar de processos qualificados de ensino e de aprendizagem que assegurem formação permanente e duradoura.

Já na Pós-Graduação em Educação, nos últimos 40 anos, ações legislativas em diferentes instâncias de governo; e planos nacionais de formação elaborados pela Coordenação de Aperfeiçoamento de Pessoal de Nível Superior-CAPES sinalizam que o paradigma predominante na qualificação do pessoal do magistério girou em torno da necessidade e da busca de suprir quadros docentes nas universidades brasileiras de mestres e doutores. $\mathrm{O}$ debate sobre a formação de professores, nesse contexto, gravitou em torno dessa busca, materializada organicamente na ênfase dada à formação de pesquisadores e não na qualificação do profissional da Educação Básica. O novo perfil da CAPES começa a alterar essa realidade em outra direção.

A partir dessa nova perspectiva, a Universidade pode inverter prioridades e contribuir com a formação do futuro professor no sentido de questionar a descontinuidade de programas, ações e políticas. Na Educação Básica, 
principalmente, não se observa a existência de ações de longo prazo planejadas por meio de um processo que envolva ampla discussão e fecunda participação dos diferentes atores interessados na qualidade do trabalho educativo desenvolvido pela escola.

Para a efetivação de ações assim planejadas é necessário que haja mobilização da população no sentido de interferir nos processos de: financiamento, gestão e democratização do espaço escolar; regulamentação do regime de colaboração; construção coletiva do projeto pedagógico; ampliação do percentual de recursos; criação de mecanismos de fiscalização e controle; organicidade entre os sistemas de ensino e as escolas, bem como entre as diversas políticas, programas e ações direcionadas à Educação Básica; condições de trabalho, de carreira e de salário; maior investimento do Fundo Público nas redes públicas de ensino (ANPED, 2006).

Lançando um olhar crítico sobre a realidade da Educação Básica e das pesquisas educacionais no Brasil, a Revista Brasileira de Educação da Associação Nacional de Pesquisa e Pós-Graduação em Educação - ANPED publicou número especial abordando os 40 anos da pós-graduação em educação em nosso país. O Parecer CFE no 977/65 é apresentado, analisado e definido como "único documento doutrinário" da pós-graduação nos últimos 40 anos. Nesse número especial da Revista, os estudiosos definem a nossa pós-graduação como estrutura híbrida que "sintetiza" os modelos norte-americano e francês. Apesar disso, nosso sistema não perde a sua natureza autóctone expressa na larga produção teórica e empírica e na diversidade de iniciativas político-institucionais (ANPED, 2005).

Dentre tais iniciativas, adotadas por diferentes instituições e diferentes grupos de pesquisas para definir e aprofundar o trabalho dos pesquisadores, destacamse: seminários permanentes de pesquisa, estágios temáticos, programas de intercâmbio, permutas de pesquisas e de informações. Iniciativas como essas contribuíram e contribuem no processo de avaliação coletiva das pesquisas produzidas, apontando debilidades e evidenciando, até mesmo, disputas políticas e ideológicas presentes no estabelecimento dos critérios de avaliação produzidos no âmbito dos programas de pós-graduação e das agências de fomento. A realidade da pós-graduação em regiões como o Norte e o Nordeste deixa clara a necessidade de rever os critérios de orientação das pesquisas, fundados na quase obrigatoriedade de publicação em revista indexadas. 


\section{A formação de professores e as pesquisa em educação: construindo relações}

O desafio da formação de novos profissionais para o quadro do magistério na Educação Básica é mundial. Nos Estados Unidos da América, na próxima década, de $30 \%$ a $40 \%$ dos docentes se aposentarão. No entanto, na realidade atual da formação de novos professores nos EUA, apenas $50 \%$ dos licenciados tornam-se professores. Para agravar o quadro, a metade dessa metade abandona o ofício durante os cinco primeiros anos de prática. Isso representa uma perda de $75 \%$ de egressos dos cursos de licenciatura (TARDIF; LESSARD, 2008).

No Brasil, a necessidade de que sejam tomadas medidas urgentes no sentido de atrair e manter os jovens na carreira é consensual entre aqueles que se dedicam à formação das novas gerações de professores. Dentre tais medidas destacam-se: estabelecer salários iniciais mais altos; fixar bons planos de carreira e melhores condições de trabalho; valorizar e melhorar a formação inicial e continuada; criar e manter boa relação com professores e colegas; resgatar na sociedade o valor do professor; tratar o professor como profissional: docência não é sacerdócio! Dados da Coordenação de Aperfeiçoamento do Pessoal do Ensino Superior - CAPES identificam fatores que levam os jovens a não se interessarem pela carreira docente: $40 \%$ indicam a baixa remuneração; $32 \%$ indicam a falta de identificação profissional ou pessoal; $17 \%$ destacam o desinteresse e o desrespeito dos alunos; $17 \%$ indicam a desvalorização social da profissão; $12 \%$ destacam as más condições de trabalho; e 15\% indicam outros fatores (CAPES, 2009).

Para enfrentar as dificuldades de recrutamento, formação e engajamento das novas gerações de professores, diferentes estratégias são adotadas. $\mathrm{Na}$ França, os esforços são dirigidos à necessidade de mudar a face do ofício de professor. Para isso pesquisadores e formadores de professores buscam adesão e consentimento dos atores envolvidos na configuração da profissão, inclusive dos jovens estudantes dos cursos de licenciatura. Essa mobilização justificase em função do fato de que posturas éticas e políticas definem e marcam o "ser professor" como profissional e em função da atividade docente não poder ser reduzida à mera prestação de serviços. Além disso, a necessidade dessa "mobilização-conversão" decorre da pluralidade dos diferentes contextos e mundos docentes (LANG, 2008). 
$\mathrm{Na}$ Inglaterra, embora o ofício de professor não tenha nascido originalmente da tradição acadêmica universitária, o fato dos docentes trabalharem em comunidades de prática - biólogos, historiadores, geógrafos, físicos, químicos, linguistas, etc. - faz com que a formação do novo professor ganhe contornos acadêmicos, universitários e, porque não dizer, científicos. Tais comunidades de prática fornecem iniciativa e potencial à formação inicial e continuada dos docentes. Em tais comunidades, os "sujeitos' que ali se mobilizam e se organizam contribuem para uma nova e promissora reconfiguração da profissão docente. Isso explica, em parte, o entusiasmo do governo inglês na promoção desse "sujeito", como alvo prioritário da formação docente, mais do que na promoção de uma determinada teoria educativa (MOON, 2008).

Na Bélgica há uma consciência de que um professor "bem formado" assumiria uma posição diante de sua própria identidade profissional. A tomada de responsabilidade (empowerment) diante dos dilemas do exercício de uma vocação, de um ofício ou de uma profissão dependeria de uma tomada de posição tanto individual como coletiva dos docentes. As escolhas organizacionais e as opções pedagógicas das escolas afetam e marcam a carreira docente. "Formar bem" o futuro professor significaria, então, implicá-lo com a vontade de dar mais lugar à palavra coletiva no ambiente escolar e fora dele. Assim, uma real profissionalização tomaria curso nos cursos de formação e no contexto escolar incorporando, inclusive, as virtualidades positivas de quem vê o trabalho docente a partir do prisma do ofício e da vocação. Esse sentido e esse significado da profissionalização, quando assumidos coletivamente, asseguram melhores condições para que o professor e a escola enfrentem melhor os problemas que surgem do cumprimento de seus objetivos diante da sociedade e os problemas que nascem do adoecimento e do mal-estar docente (MAROY, 2008).

A adoção de claras posturas éticas e coletivas em torno de comunidades de prática contribui para o fortalecimento das pesquisas em educação e para o processo de valorização da formação inicial e continuada dos docentes. Tais posturas levam as comunidades de formadores a se indagarem sobre as seguintes questões: quais os critérios para que os jovens sejam admitidos nos cursos de formação e na carreira docente? Como avaliar o aluno no início, no meio e no fim e um curso de formação inicial? Como acompanhar e pesquisar a trajetória do egresso? Como identificar jovens capazes de se tornarem bons professores? Como reorientar aqueles que no percurso não revelem as aptidões necessárias? As provas de 
excelências acadêmicas são suficientes? Como relacioná-las às avaliações de outros aspectos tais como capacidade de empenhar numa formação profissional orientada pela prática reflexiva?

Os profissionais dos cursos de formação docente analisam tais questões e buscam respostas que afirmem e reconheçam a importância de se prestar contas à sociedade, sem renunciar à autonomia de iniciativas; que indiquem no sentido de sua função pública, sem ficar a reboque das opções políticas do momento; que fortaleçam a visão construtiva, típica do meio escolar, sem abandonar postura crítica, típica do meio universitário. Para isso, é necessário entender que as estruturas estabelecidas não são fins em si mesmas. Elas são apenas meios. O importante é que se produzam e que se compartilhe com os novos professores em formação uma relação crítica e científica com as pesquisas e com os saberes, apontando na direção de uma formação universitária consistente (PERRENOUD, 2008).

No entanto, a busca de status universitário "stricto sensu" pelos centros de formação docente não garante em si implicação crítica e postura reflexiva. Não é porque a universidade detém o saber erudito e faz pesquisas que ela é capaz, apenas por isso, de formar bons professores. Para que ela possa cumprir esse papel, o abandono de velhos hábitos é imprescindível. Se ela fizer isso, ela poderá ser o lugar, por excelência, dessa formação. Para que isso ocorra, é necessário que a ênfase seja dada na profissionalização do trabalho e na dimensão reflexiva. A profissionalização docente, nessa perspectiva, inclui, por um lado, pensamento crítico e autônomo, e, por outro, domínio de saberes teóricos e metodológicos enraizados na pesquisa. Essa postura afasta o novo professor de regulações técnicas, autorizando reflexões acerca das culturas em jogo, do processo de constituição das identidades e do estabelecimento das finalidades educativas.

Nesse debate sobre as pesquisas em educação e sobre a formação docente, é importante ressaltar, ainda, a idéia segundo a qual nas "pesquisas científicas" no campo educacional é urgente solucionar o problema dos pontos de partida e da memória. Enquanto as ciências duras avançam cumulativamente a partir de seus pontos de chegada, as ciências do homem, a exemplo das ciências em educação, avançam de outra maneira. Elas avançam e "acumulam" a partir de seus pontos de partida e não de seus pontos de chegada. Só há avanços nessas ciências quando elas propõem novas formas de começar. Não há acumulação em ciências humanas. Nelas só há memória. O ponto de apoio das pesquisas em educação, portanto, é o saber já 
produzido. Antes, durante e depois de nossas pesquisas, perguntar e conhecer como nos relacionamos com aquilo que já sabemos é fundamental. Não podemos ensinar, aprender e avaliar sempre da mesma maneira, esquecendo do passado e do futuro. Não podemos fazer e refazer continuamente as mesmas teses, as mesmas dissertações, os mesmos artigos. Para não repetir ad infinitum, é fundamental não nos esquecermos das pesquisas e dos debates que aconteceram em décadas, anos e meses anteriores. É a falta de memória que bloqueia o avanço das pesquisas em educação. Com efeito, é imprescindível inventariar a memória coletiva das pesquisas e contribuir para garantir o amadurecimento qualificado das pesquisas educacionais. Esse é um horizonte teórico-metodológico promissor para a Educação Básica, para a pós-graduação em educação e para a construção de relações entre as duas (CHARLOT, 2006).

Para quem trabalha com formação de professores, é necessário inventariar as pesquisas e as políticas públicas desenvolvidas nos últimos anos. A eficácia e a qualidade do sistema educacional brasileiro, da Educação Infantil à Pós-Graduação, da escola básica à educação superior, do ensino das noções elementares às pesquisas científicas em educação dependem da responsabilidade coletiva e compartilhada entre as organizações da sociedade civil, o poder público (Municípios, Estados e União) e os profissionais da educação envolvidos. Isso poderia nos impedir de repetir acriticamente muitos caminhos já trilhados nas pesquisas e nas políticas buscando um sentido mais "científico" e evitando discrepâncias, dissonâncias e cacofonias desnecessárias (BOOTE et al., 2008).

\section{As Políticas Educacionais: Aproximando a Universidade e a Escola de Educação Básica}

No mundo inteiro, entre os profissionais da ativa e entre os estudantes matriculados em cursos de formação docente algumas perguntas são reiteradamente repetidas nos corredores, nas salas de aulas, em seminários, simpósios e congressos educacionais e pedagógicos: o que significa ser professor nos dias de hoje? Os professores da ativa e os futuros mestres são chamados a cumprirem uma vocação? São chamados a exercer um ofício nobre? São convocados a assumir uma profissão cada vez mais proletarizada? Quais são, de fato, os sentidos e os significados de uma real profissionalização da carreira docente na pós-modernidade?

No Brasil, as políticas educacionais voltadas para a formação inicial e continuada de professores partem da constatação de que é imprescindível a valorização e a 
construção de uma cultura de parcerias e de cooperação entre as universidades, o Estado e as escolas de Educação Básica e diferentes organizações da sociedade civil. $\mathrm{O}$ envolvimento com as escolas de Educação Básica pressupõe a identificação e a consideração dos instrumentos e dos recursos didáticos disponíveis e ao alcance dos profissionais desse nível de ensino. Além disso, pressupõe o respeito a estes profissionais, pois a escola de Educação Básica, muitas vezes sozinha e sem apoio, administra problemas, inclusive sociais, que para ela são encaminhados e que se manifestam nas práticas e nos comportamentos cotidianos dos alunos, dos pais e dos professores (LELIS, 2008).

Para os centros formadores existe uma clareza de que a formação profissional do futuro docente só pode ocorrer a contento em parceria com a comunidade dos docentes que já atuam na Educação Básica. Sem esse envolvimento, tal formação não se efetiva. Esse processo de envolvimento e de interação, notadamente nas atividades de estágio, pode alienar parte da autonomia da universidade e dos centros formadores. É como diz o ditado: "Esse é o preço que se paga". Muitas vezes a universidade evita tal envolvimento com pessoas ou com corporações procurando não correr esse risco de perda de autonomia nos debates sobre os pressupostos teóricos e metodológicos da formação inicial e continuada dos docentes. No entanto, são necessárias ações que aproximem a universidade das demandas sociais. A formação dos novos professores depende da contribuição efetiva dos profissionais da escola de Educação Básica. Essa contribuição nem sempre ocorre a partir dos pressupostos e das concepções das agências formadoras. Nesse caso, os centros formadores perdem parte de sua autonomia, pois para cumprir suas metas de formar professores eles contam necessariamente com sujeitos formadores que não estão sob sua orientação plena.

Para a escola básica, as múltiplas pressões exercidas sobre o espaço e o tempo escolares não podem mais ser ignoradas quanto se trata de discutir os fundamentos da formação docente. A permeabilidade, marcada por ações com lógicas heterogêneas, entre contexto interno e contexto externo à prática pedagógica pode significar, ao mesmo tempo, importante recurso e grave obstáculo. Os pais, por exemplo, apresentam-se para as escolas como consumidores de seus produtos e como parceiros em ações propostas. $\mathrm{O}$ valor da participação democrática pode ficar ofuscado pela lógica competitiva do "mercado escolar". Tal mercado é disputado a partir da construção de uma determinada imagem do estabelecimento que, muitas vezes, é marcada por idéias de reputação, de performance e de desempenho, típicos do ambiente concorrencial (LANG, 2008). 
Isso mostra o quanto é importante discutir a aproximação entre as pontas do sistema. Educação infantil, ensinos fundamental e médio, graduação e pósgraduação se reencontram por meio de sólidas estratégias de ensino, pesquisa e extensão. Pedagogos e licenciados, bacharéis e pesquisadores, quando respondem coletivamente às demandas urgentes de qualificação da educação nacional, não empurram para o outro a "culpa" pelo fracasso da escola. A melhoria na qualidade da escola e na formação do futuro professor, aluno de nossas licenciaturas, são condições para o aperfeiçoamento de todo o sistema escolar brasileiro.

Diversos grupos de pesquisa em todo território nacional, articulados em tornos de programas de pós-graduação; de eventos locais, regionais, nacionais e internacionais; de periódicos, associações e revistas científicas se dedicam ao trabalho de valorização do magistério e de aperfeiçoamento da formação do professor. É fundamental o apoio a este esforço, identificado entre os pesquisadores da pós-graduação em educação e entre os profissionais da Educação Básica e do Ensino Superior. Esforço que visa a consolidar as pesquisas científicas na área. Área marcada por tensões oriundas de diferentes demandas sociais materializadas nas políticas educacionais. A ciência da área se configura por meio da política. A política da área, por sua vez, se configura por meio dos resultados das pesquisas educacionais.

No campo das políticas educacionais identificamos ações e proposições que visam a promover a articulação entre diferentes áreas que oferecem licenciaturas e estabelecer diretrizes gerais para a formação de professores. O objetivo maior tem sido garantir a profissionalização do professor em torno de eixos comuns e competências básicas referidas às especificidades do trabalho desse profissional, efetivando por meio de ações integradas uma formação que assegure e construa um profissional com identidade própria. Para isso, os cursos de licenciaturas buscam superar a condição atual em que eles tornam-se apenas apêndices dos cursos de bacharelado. Em estudo anterior analisamos a questão da valorização das licenciaturas no interior das universidades (SOARES, 2006, 2011).

Nessa mesma direção, a recente criação do Conselho Técnico-Científico da Educação Básica - CTC/EB - objetiva, dentre outras coisas, avaliar a qualidade dos cursos de licenciatura da mesma maneira que a Ordem dos Advogados do Brasil e o Conselho Nacional de Medicina avaliam os cursos de suas respectivas áreas. Embora a importação de modelos de outras áreas seja problemática, o CTC/EB, se bem articulado, poderá ser importante espaço de integração entre 
Educação Básica e superior no esforço conjunto de qualificar a formação inicial e continuada do professor que resulte em aperfeiçoamento dos mecanismos de acesso, permanência e de qualidade da escola brasileira, identificando demandas, abrindo diálogo constante com as realidades regionais e fomentando pesquisas.

A compreensão da necessidade de fortalecer as licenciaturas e a carreira docente é reforçada pelos membros do Conselho Técnico Científico da Educação Básica CTC/EB - quando propõem ao Conselho Técnico Científico da Educação Superior - CTC/ES - que considere como obstáculo à boa formação de professores: a não valorização, na avaliação do docente do ensino superior, da dedicação ao ensino de graduação; a não identificação na Plataforma Lattes da produção didáticopedagógica das atividades na graduação; o não incentivo, pelo CNPq de inovações e de permanência de bons professores por meio de bolsas de mérito didático na graduação; o não financiamento suplementar às IES que se dedicam à formação inicial e continuada dos professores da Educação Básica.

Outra política pública educacional visando a inverter essa situação e a aproximar a universidade da escola básica é o Programa de Consolidação das Licenciaturas Prodocência - que adota como diretrizes fundamentais: aglutinação dos diferentes cursos de licenciaturas em torno de uma proposta de formação de professores na IES; ampliação das oportunidades de acesso/intercâmbio acadêmico, visando a qualificação de um maior número de profissionais para a Educação Básica; incentivo a experiências de caráter inovador que busquem a superação de problemáticas históricas da Educação Básica brasileira; valorização de projetos que contemplem uma associação do ensino com a pesquisa de forma a consolidar uma formação voltada para a prática pedagógica reflexiva; o espaço da escola, com a riqueza que ele oferece como campo de experiência, para a construção do conhecimento na formação dos profissionais da educação; a incorporação crescente de estudantes de Pedagogia e das Licenciaturas em projetos vinculados à Rede de Ensino Pública; incentivo para projetos que utilizem novas tecnologias de informação, que sejam multidisciplinares e temáticos, propondo alternativas teóricas, investigativas e metodológicas.

O êxito do CTC/EB e de outras medidas das políticas educacionais expressas nas proposições do Prodocência, por exemplo, dependem de uma articulação de diversas lideranças educacionais mobilizadas nas diferentes pontas do sistema escolar. Essa articulação reverbera no interior dos cursos de licenciatura através da 
aglutinação de propostas comuns de formação inicial e continuada de professores que assegurem o acesso aos cursos, a permanência neles e a conseqüente formação qualificada. As inovações por meio de práticas pedagógicas reflexivas podem contribuir para essa formação de qualidade desde que o espaço da escola seja de fato reconhecido como importante lugar para construção de conhecimentos e para a troca de experiências, efetivando o princípio da interatividade dialética entre teoria e prática, pois não há prática que não expresse alguma teoria e não há teoria que não expresse alguma prática. A experiência da UFVJM procura caminhar nessa direção.

\section{Prodocência na Universidade Federal dos Vales do Jequitinhonha e Mucuri - UFVJM: o envolvimento com as escolas de Educação Básica}

A proposta de formação de professores para a Educação Básica na UFVJM considera a profissão docente como atividade complexa e de alto nível. Por isso mesmo, destaca a importância de desenvolver estudos acerca: a) da natureza do ofício de professor; b) do valor da pesquisa como elemento de ligação entre a formação inicial e o exercício profissional; c) do envolvimento dos cursos de pós-graduação com a realidade da graduação e da Educação Básica; e d) do papel indutor das políticas educacionais no sentido de fixar a aproximação entre a Universidade e a Escola Básica como meta fundamental para a ação em todas as instâncias dos sistemas educacionais em nível municipal, estadual e federal. Nessa perspectiva, as reflexões oriundas de tais estudos evidenciam que a proposta da UFVJM visa a promover esse envolvimento, efetivando a valorização do magistério da Educação Infantil ao ensino superior, a partir das demandas locais e da realidade nacional. O Programa de consolidação das licenciaturas Prodocência - é parte dessa estratégia.

O Projeto Prodocência da UFVJM para os cursos de licenciatura de Matemática, Ciências Biológicas, Química e Educação Física, intitulado Envolvimento entre a Universidade e a Escola de Educação Básica dos Vales do Jequitinhonha e Mucuri: fortalecimento das licenciaturas, aprovado pela Fundação Coordenação de Aperfeiçoamento de Pessoal de Nível Superior - CAPES, encontra-se em desenvolvimento. O Projeto envolveu na sua proposição professores dos quatro cursos de licenciaturas e prevê a realização de atividades que conjugam três dimensões: o ensino, a pesquisa e a extensão. São elas: 1) Diagnóstico dos cursos 
e das escolas públicas de Educação Básica das regiões dos Vales do Jequitinhonha e Mucuri; 2) Estruturação do Núcleo de Estudos e de Memória das Licenciaturas - NEMEL; e 3) Realização do Seminário de Pesquisa e Prática Pedagógica.

$\mathrm{Na}$ análise diagnóstica, estão sendo coletados dados e informações sobre a história da educação escolar da região e sobre os projetos pedagógicos das licenciaturas, os resultados das avaliações dos Cursos e o perfil dos corpos discente e docente. $\mathrm{Na}$ estruturação do NEMEL, por exemplo, o maior objetivo é o oferecimento de um espaço e de um tempo propícios à interlocução entre formadores, licenciandos e professores da Educação Básica. O Núcleo conta com espaço físico e seu acervo será armazenado e disponibilizado em ambiente virtual. Além disso, durante a análise diagnóstica e a organização do Núcleo, a realização dos Seminários de Pesquisa e Prática Pedagógica fomenta a troca de experiências e o conhecimento acerca da rede pública de Educação Básica da região.

A construção de um banco de dados consistente permite diagnosticar a realidade das escolas de Educação Básica, que demandam a formação do professor; e a realidade dos cursos de licenciatura da Universidade, que têm a tarefa de oferecer a formação inicial desse professor. Nos Vales do Jequitinhonha e Mucuri são 1729 (hum mil e setecentos e vinte e nove) escolas públicas, distribuídas em 98 municípios, que atendem a 407.301 (quatrocentos e sete mil e trezentos e um) estudantes matriculados nas escolas da região, da Educação Infantil ao ensino médio. Além de conhecer a realidade da escola básica, o projeto busca conhecer o perfil dos estudantes que ingressam nas licenciaturas. Quem são os estudantes que ingressam nos cursos de licenciatura da UFVJM?

Para responder a essa pergunta e para aprofundar o conhecimento do perfil sócio-cultural dos estudantes, pesquisa permanente está sendo realizada com os licenciandos. Dados preliminares recolhidos entre alunos que cursam o $2^{\circ}, o$ $3^{\circ}$, o $4^{\circ}$ e o $7^{\circ}$ períodos dos cursos de ciências biológicas, de educação física e de química, através de amostra aleatória, revelam informações importantes. A pesquisa procurou, dentro outros aspectos, identificar as ocupações profissionais dos pais, o nível de renda familiar e o nível de escolaridade de pais e avós.

Em relação ao perfil familiar dos estudantes de licenciatura no que se refere ao número de membros na família, à ocupação profissional, à renda e à escolaridade, os dados revelaram que a maioria dos entrevistados pertence a famílias com menos de três filhos, que mais da metade de pais e mães exercem funções profissionais 
que não demandam escolarização; que quase a totalidade das famílias têm renda abaixo de 5 salários mínimos; que praticamente a totalidade dos avós não tiveram acesso ao ensino superior; que $27,53 \%$ das mães e apenas $8,9 \%$ dos pais ingressaram na universidade (UFVJM, 2010).

Em relação ao perfil, às expectativas de futuro e às origens geográficas dos estudantes de licenciatura, concluímos que a maioria é do sexo feminino, com menos de 25 anos de idade e oriunda de escola pública, sendo que $63 \%$ declararam ter feito cursinho para entrar na Universidade. De todos os entrevistados, apenas $21,63 \%$ afirmaram que pretendem ser professores. No caso dos cursos de licenciatura, a UFVJM tem cumprido seu papel regional de dar acesso à Universidade aos estudantes nascidos no interior de Minas Gerais e nos Vales do Jequitinhonha e Mucuri, pois 74\% deles são oriundos dessas regiões.

Os dados preliminares da pesquisa realizada internamente no âmbito do Prodocência com alunos da UFVJM foram confrontados com os dados da avaliação externa realizada pelo MEC/INEP através das avaliações do ENADE. Os dados do ENADE se referem apenas aos estudantes ingressantes nas licenciaturas. Não foi possível aferir esses dados em relação aos ingressantes de Educação Física. Os dados dos estudantes de matemática não foram divulgados até a data do fechamento desse texto. Os ingressantes foram avaliados com o objetivo de aferir desempenho em relação a conteúdos, habilidades e competências (BRASIL, 2009).

O desempenho geral dos estudantes ingressantes de licenciatura nos cursos de ciências biológicas, de educação física e de química da UFVJM no ENADE 2007, cujos resultados foram divulgados em 2008 e 2009, revela que a média geral desses estudantes é de 27,76 enquanto a média nacional é de 34,83. Na prova que aferiu o domínio de conteúdos de formação geral, a média é de 39,46 enquanto a média nacional é de 46,63. Na prova do ENADE que aferiu o domínio de conteúdos de formação específica dos estudantes ingressantes de licenciatura da UFVJM a média é de 23,8 , enquanto a média nacional é de 30,9. Os nossos estudantes ingressantes estão, em média, sete pontos abaixo da média dos demais estudantes brasileiros. Quando se considera o fato de se declararem brancos, negros, pardos e/ou mulatos o resultado foi o seguinte: $51,25 \%$ declararam ser brancos e apresentaram nota média de 36,$7 ; 10,8 \%$ declararam ser negros e apresentaram nota média de 41,$95 ; 35,9 \%$ declararam ser pardos e/ou mulatos e apresentaram nota média de 37,15. 
O desempenho dos estudantes dos cursos de licenciatura em ciências biológicas e em química da UFVJM quando se considera a renda familiar declarada no questionário sócio-econômico do ENADE mostrou o seguinte resultado: 44,45\% declararam ter renda familiar até três Salários Mínimos e apresentaram nota média de 36,$45 ; 29 \%$ declararam ter renda familiar de três até 10 Salários Mínimos e apresentaram nota média de 41,4; 7,6\% declararam ter renda familiar de 10 a 20 Salários Mínimos e apresentaram nota média de 38,05. Quando se considera a escolaridade do pai o resultado foi o seguinte: $4,55 \%$ dos estudantes cujos pais não tiveram nenhuma escolaridade obtiveram nota média de 20,$55 ; 20,8 \%$ cujos pais estudaram apenas até a $4^{\mathrm{a}}$ série do Ensino Fundamental obtiveram nota média 38,3; $19,35 \%$ cujos pais estudaram até a $8^{\text {a }}$ série do Ensino Fundamental obtiveram nota média de 36,$55 ; 25,1 \%$ cujos pais cursaram Ensino Médio obtiveram nota média de 38,$05 ; 30,2 \%$ cujos pais cursaram Ensino Superior obtiveram nota média de 39,25. Quando se considera a escolaridade da mãe o resultado foi o seguinte: $2,25 \%$ dos estudantes cujas mães não tiveram nenhuma escolaridade obtiveram nota média de 16,$85 ; 10,8 \%$ cujas mães estudaram apenas até a 4 a série do Ensino Fundamental obtiveram nota média 36,$75 ; 17,35 \%$ cujas mães estudaram até a $8^{\mathrm{a}}$ série do Ensino Fundamental obtiveram nota média de 36,4; 46,2\% cujas mães cursaram Ensino Médio obtiveram nota média de 39;14\% cujas mães cursaram Ensino Superior obtiveram nota média de 38,15 .

Conforme fica evidenciado, os dados da cor da pele e da renda familiar dos ingressantes revelam que esses dois aspectos não produzem efeitos expressivos no desempenho dos estudantes na prova do ENADE, ou seja, a ligeira vantagem dos negros em relação a brancos e pardos, e a ligeira vantagem daqueles com renda familiar entre três e dez salários mínimos não significam que a renda e a cor da pele, no caso desses ingressantes, alterem substancialmente o desempenho e o percurso escolares desses estudantes.

Todavia, em relação à escolaridade de pais e mães, a pesquisa revelou outra situação, pois os filhos de pais com alguma escolaridade têm desempenho até 19 pontos acima dos filhos de pais sem escolaridade. No caso das mães, essa diferença chega a atingir 23 pontos, ou seja, se a cor e a renda não impactam significativamente no desempenho dos ingressantes, o mesmo não se pode dizer do nível de escolaridade de pais e mães, conforme dados apresentados acima. 
Os estudos no âmbito do Projeto Prodocência ainda são preliminares e consideram que as pesquisas sobre a prática do professor e sobre a sua formação são atividades complexas e de alto nível, ou seja, elas valem mais pelos seus pontos de partida do que por seus pontos de chegada, conforme indica Bernard Charlot (2006). O objetivo maior desse projeto é a produção de um inventário da memória das práticas de ensino, de pesquisa e de formação de professores na região e no Brasil visando a envolver a Universidade com as escolas de Educação Básica e a contribuir assim para a efetiva valorização do magistério da Educação Infantil ao ensino superior.

\section{Considerações finais}

Para concluir provisoriamente as reflexões apresentadas até aqui, reiteramos que as pesquisas em educação em nível de pós-graduação são mais consistentes quando consideram o importante papel indutor das políticas educacionais no sentido de provocar uma aproximação produtiva entre o trabalho das Universidades e o trabalho dos profissionais da Escola Básica. $\mathrm{O}$ aprofundamento das pesquisas sobre a natureza do ofício de professor e sobre a importância de articular a formação inicial do futuro docente da prática profissional do professor que já se encontra na ativa contribuirá para fortalecer e qualificar a Educação Básica, a graduação e a pós-graduação. No caso específico dos cursos de licenciatura, torna-se urgente o enfrentamento de alguns desafios no âmbito das universidades.

Nas universidades, públicas ou privadas, com faculdades de educação constituídas e consolidadas, que gozam de massa crítica oriunda das pesquisas do campo educacional, a tensão mais visível manifesta-se externamente entre a formação específica, oferecidas nas unidades de origem e a formação pedagógica, oferecida nas faculdades de educação. Nas universidades sem faculdades de educação, como é o caso da UFVJM, a tensão mais visível manifesta-se internamente entre disciplinas tradicionalmente ligadas às licenciaturas e as disciplinas tradicionalmente ligadas aos bacharelados. Nas duas situações verifica-se pouca consistência curricular. Na primeira situação, a polarização externa tende a anular a riqueza da massa crítica já consolidada. Na segunda, a polarização interna leva a um relativo abandono da licenciatura como campo de pesquisa, ensino e extensão, mesmo em cursos destinados especificamente a formar professores, acentuando a dissociação 
entre a formação de professor e a pesquisa educacional. O diálogo entre os pesquisadores das áreas da educação e os pesquisadores das áreas específicas, superando desconfianças mútuas, tanto na primeira quanto na segunda situação, poderá contribuir para dar outra qualidade aos cursos de formação inicial dos professores (SOARES, 2011).

Na linha histórica pela superação de tais problemas, conflitos e tensões é necessário elaborar projetos de estudos, pesquisa e práticas a partir de aproximações consistentes e produtivas entre esses dois campos de pesquisas. Para isso, tornase fundamental a socialização de experiência e de questionamentos, a produção de novas reflexões e de novas idéias, a articulação de grupos envolvidos com a formação inicial de professores. Esse conjunto de ações permitirá a busca de soluções que equacionem tais dilemas. Convergências, divergências, diferenças, contradições, e também pontos em comum, tanto nas práticas de pesquisa, quanto nas práticas de ensino, quando socializadas em diferentes espaços e fóruns, ganham visibilidade e prestam serviço às comunidades envolvidas. A rica e diversificada produção acadêmica nos campos do trabalho do professor, da formação docente e das práticas educativas, quando amplamente disseminada, possibilita a reorganização dos projetos pedagógicos dos cursos de graduação, o aprofundamento de temáticas similares e a ampliação da compreensão da produção teórica oriunda de diferentes espaços educativos. Tais questões mostram que os "ensaios intermitentes" presentes e recorrentes na história da formação docente no Brasil serão superados a partir da aproximação cada vez maior entre Educação Básica, graduação e pós-graduação. Para isso, a nova CAPES poderá jogar papel preponderante.

\section{Referências}

ANPED. ASSOCIAÇÃO NACIONAL DE PESQUISA E PÓS-GRADUAÇÃO EM EDUCAÇÃO. Editorial: 40 anos de pós-graduação em educação no Brasil. Revista Brasileira de Educação, n. 30, número especial, set./out./nov./dez, 2005.

\footnotetext{
ANPED. ASSOCIAÇÃO NACIONAL DE PESQUISA E PÓS-GRADUAÇÃO EM EDUCAÇÃO. Política e Gestão da Educação Básica, 2006. Disponível em: $<$ www.anped.org.br>. Acesso em: 15 jul. 2010.
} 
BOOTE, D.; et al. O. Da história e do futuro da formação de professores no Canadá inglês: a tradição na prática dos formadores dos professores. In: TARDIF, M.; LESSARD, C. O oficio de professor: história, perspectivas e desafios internacionais. Petrópolis, RJ: Vozes, 2008.

BRASIL. Relatório do Exame Nacional de Avaliação Discente dos cursos de Ciências Biológicas, Educação Física e de Química da UFVJM. Brasília, DF: ENADE/ MEC/ INEP, 2009.

CAPES. COORDENAÇÃO DE APERFEIÇOAMENTO DO PESSOAL DE NÍVEL SUPERIOR. Pronunciamento da Diretoria de Educação Básica Presencial da Capes. Brasília, DF: CAPES, 2009. Disponível em: <www.mec. gov.br em julho de 2010>. Acesso em: 15 jul. 2010.

CHARLOT, B. A pesquisa educacional entre conhecimentos, políticas e práticas: especificidades e desafios de uma área de saber. Revista Brasileira de Educação, Rio de Janeiro, v. 11, n. 31, jan./abr., p. 7-18, 2006.

LANG, V. A profissão do professor na França: permanência e fragmentação. In: TARDIF, M.; LESSARD, C. O oficio de professor: história, perspectivas e desafios internacionais Petrópolis, RJ: Vozes, 2008.

LELIS, I. A construção social da profissão docente no Brasil: uma rede de histórias. In: TARDIF, M.; LESSARD, C. O oficio de professor: história, perspectivas e desafios internacionais. Petrópolis, RJ: Vozes, 2008.

MAROY, C. O modelo do prático reflexivo diante da enquete na Bélgica. In: TARDIF, M.; LESSARD, C. O ofício de professor: história, perspectivas e desafios internacionais. Petrópolis, RJ: Vozes, 2008.

MOON, R. As políticas reformistas: transição na formação dos professores na Inglaterra. In: TARDIF, M.; LESSARD, C. O oficio de professor: história, perspectivas e desafios internacionais. Petrópolis, RJ: Vozes, 2008.

PERRENOUD, P. As Altas Escolas Pedagógicas (HEP) suíças entre a forma escolar e a forma universitária: as questões. In: TARDIF, M.; LESSARD, C. O oficio de professor: história, perspectivas e desafios internacionais. Petrópolis, RJ: Vozes, 2008. 
SOARES, A. S. Bacharel ou licenciado: ser ou não ser, eis a questão. In: ENCONTRO NACIONAL DE EXTENSÃO, 13., 2006, Minas Gerais. Anais... Belo Horizonte: PUCMinas, 2006.

SOARES, A. S. Licenciatura versus bacharelado: a cultura da polarização na formação inicial dos professores. Poiesis Pedagógica, Goiás, v. 9, n.1, jan/jun., p.109-123, 2011.

TARDIF, M.; LESSARD, C. O oficio de professor: história, perspectivas e desafios internacionais. Petrópolis, RJ: Vozes, 2008.

UFVJM. UNIVERSIDADE FEDERAL DOS VALES DO JEQUITINHONHAE MUCURI. Prodocência: diagnóstico das licenciaturas, 2010. (Relatório parcial mimeografado).

\section{The development of teacher formation in elementary education between public policy and educational research: an experience in the Valley of Jequitinhonha in Minas Gerais. Abstract}

The study presents an examination on the duty of teaching, and corroborates the value of educational research as a link between the primary formation of future teachers and present-day teachers. The text highlights the importance of postgraduate projects as a result of the dialogue between the teaching courses and the reality on the Brazilian schools of Elementary Education. Moreover, this work emphasizes the impelling role of educational policies with the objective of bringing closer University and Elementary School as the main goal of the government effort on all levels of Brazilian education structure. The project "Prodocencia of UFVJM", which aims at strengthening the teacher formation courses resulting from the close relation and dialogue, is presented as a case of such impelling role of educational policies.

Keywords: Elementary education. Educational policies. Postgraduation in Education. "Prodocência" of UFVJM. 


\section{La formación del profesor de escuela Primaria entre políticas públicas e investigaciones educacionales: una experiencia en el valle de Jequitinhonha en Minas Gerais - Brasil}

\section{Resumen}

El estudio presenta reflexiones sobre la naturaleza de la profesión docente, reafirmando el valor de la investigación educacional como un enlace entre la formación inicial de los futuros maestros y la práctica efectiva del maestro en el aula. El texto señala la importancia de que los proyectos de posgrado en educación se desarrollen a partir de un diálogo con los cursos de formación de profesores y con la realidad de las escuelas primarias brasileñas. Además, el trabajo confirma el rol inductor de las políticas educacionales con el objeto de acercar la Universidad a la Escuela Primaria como meta fundamental para la acción pública en todas las instancias del sistema educacional brasileño. El proyecto Prodocencia de la UFVJM -Universidad Federal de Valle de Jequitinhonha y Mucuri, que busca consolidar los cursos de licenciatura a partir de este enfoque y de ese tipo de diálogo se presenta como un ejemplo de papel inductor de las politicas públicas educacionales.

Palabras claves: Educación primaria. Políticas educacionales. Posgrado en Educación. Prodocencia de UFVJM. 